nach dem Erkalten mit Natronlauge in genügender Menge gefällt. Der in Lösung bleibende Theil der Harzsäuren wird aus der filtrirten Flüssigkeit durch Neutralisiren mit Säure abgeschieden. Die den grössten Theil des Harzes einschliessende gefällte Seife löst man in sehr wenig heissem Wasser und versetzt mit überschüssiger Chlorbaryumlösung; die mit Hülfe der Luftpumpe abgesogene, gefällte Barytseife wird völlig getrocknet, gepulvert und mit heissem 85 procentigem Alkohol vollständig extrahirt. Aus den filtrirten, auf ungefähr $50 c c$ abdestillirten Flüssigkeiten wird das Harz mit Salzsäture abgeschieden und nach dem Umschmelzen über Wasser und Trocknen gewogen. Aus der extrahirten Seife können auch die fetten Säuren abgeschieden werden.

Die Methoden zur Untersuchung von Schmierölen stellt F. Fischer*) in längerer Abhandlung zusammen. Da dieselbe wesentlich Neues nicht bringt, sō kann hier nur auf das Original verwiesen werden.

Zur Unterscheidung des Oliven- ron Baumollsamenöl benutzt Benjamin Nickels**) die Verschiedenheit der Absorptions-Spectren dieser Oele. Olivenöl (Gallipoli) erzeugt im Blau und Violett einen tiefen Schatten, besitzt eine feine, fast undeutliche Linie im Grün und ein starkes dunkles Band im Roth. Raffinirtes Baumwollsamenöl zeigt im Blau und Violett keinen Unterschied von Olivenöl, während das Spectrum im Grün und Roth continuirlich ist.

Auf ein zur Prüfung der Oele von Pinchon***) angegebenes Aräometer (aréomètre thermique) kann hier nur aufmerksam gemacht werden, da die Ermittelung des specifischen Gewichtes bei Oeluntersuchungen wohl schon längst allgemein üblich ist.

\title{
Zur Bestimmung der entfärbenden Kraft verschiedener Sorten
} von Knochenkohle $\dagger$ ) durch quantitative Spectralanalyse benutzt C. H. Wolf $f \dagger$ ) eine Modification des von v. Vierordt $+\dagger^{\dagger}$ ) gegebenen Verfahrens. Je $8 g$ der staubfreien, grobkörnigen Knochenkohle werden

*) Dingler's polyt. Journ. 236, 487.

**) Chem. News 42, 27.

***) Moniteur scientifique [3. série] 10, 1121.

†) Vergl. diese Zeitschrift $\mathbf{9}, 406 ; \mathbf{1 3}, 83$.

†) Corr.-Bl. d. Ver. analyt. Chemiker, im Separatabdruck vom Verfasser eingesandt.

$+\dagger+$ ) Vergleiche diese Zeitschr. 10, 351, 486; 11, 429; 15, 353; ferner von Vierordt, "Die quantitative Spectralanalyse", Tübingen 1876, p. 1-21. 
mit $24 c c »$ Probemelasse « (eine auf das Vierfache verdünnte, dunkel rothbraune Melasse) in einem mit Kork lose verschlossenen kleinen Glaskolben $1 / 2$ Stande im vollen Dampfbade erwärmt und darauf noch 1/2 Stunde zum Erkalten bei Seite gestellt. Während dieser Stande wird der Kolben mit Inhalt alle 10 Minuten 2-3 mal umgeschwenkt und dann die noch mehr oder weniger gefärbte Probemelasse sofort abfiltrirt. Es wird nun der Ausdruck für den relativen Farbstoffgehalt der Probemelasse vor und nach der Entfärbung mit Kohle durch Messung der übrig bleibenden Lichtstärke des Absorptionsspectrums in der für diese Bestimmungen geeignetsten Region F-F $10 \mathrm{G}$ nach den Angaben v. Vierordt's gewonnen, und hieraus die von der Kohle absorbirte Farbstoffmenge wie auch der Entfärbungscoëfficient berechnet. Nach v. Vierordt ist der Coëfficient $\mathbf{j}$ als Ausdruck für die entfärbende Kraft der Kohle um so kieiner, je grösser der Wirkungswerth der Kohle ist. Innerhalb ziemlich weiter Grenzen des Volumens (v), des Farbstoffgehaltes (c) der zu entfärbenden Flüssigkeit, sowie der Menge $\mathrm{k}$ der zur Entfärbung verwendeten Kohle ist $\mathrm{j}=\frac{\mathrm{fk}}{\mathrm{V} \mathrm{c}^{2}}$.

Da die absolute Menge des Farbstoffes der Syrupe unbekannt ist, so stellen $c$ und $f$ (Farbstoffgehalt der Probemelasse nach theilweiser Entfärbung durch die Kohle) nur relative Werthe dar. Da ferner der in irgend einer Region des Absorptionsspectrums einer farbigen Flüssigkeit gemessene Extinctionscoëfficient dem Gehalte der Flüssigkeit an gefärbter Substanz proportional ist, so erscheint es am einfachsten, den Extinctionscoëfficienten als Maass des relativen Farbstoffgehaltes der Zuckersyrupe zu benutzen. Bleiben bei der Bestimmung der entfärbenden Kraft der Kohle Volumen and Farbstoffgehalt des Zuckersyrups in allen Fällen unverändert, sodass $\frac{\mathrm{k}}{\mathrm{v} \cdot \mathrm{c}^{2}}$ durch eine Constante C ersetzt werden kann, sō hat man $\mathrm{j}==\mathrm{f}$. C, d. h. der relative Werth der Kohle als Entfärbungsmittel wird ausgedrückt durch den Extinctionscoëfficienten (resp. Farbstoffgehalt des Filtrates). Da aber in der Praxis schwerlich immer Syrupe von genau gleichem Farbstoffgehalt zur Verfügung stehen, so ist zu empfehlen, nur die Kohlenmengen, das Volumen des Syrupes, sowie die Art und Weise des Contactes bei allen Einzelbestimmungen constant zu nehmen. Wird der Syrup in einem grösseren Vorrathe aufbewahrt, so reicht selbstverständlich die einmalige Bestimmung seines Farbstoffgehaltes für alle Einzelversuche aus. Man verfährt also bei der Werth- 
bestimmung der Kohle kurz so, dass man nach geschehener theilweiser Entfürbung, wie oben beschrieben, den Syrup filtrirt und ein Absorptionsspectrum desselben bei einer $1 \mathrm{~cm}$ dicken Flüssigkeitsschicht herstellt, sodann die übrigbleibende Lichtstärke dieses Spectrums in der Region F-F $10 \mathrm{G}$ misst und in der Tabelle den dieser Lichtstärke entsprechenden Extinctionscoëfficienten aufschläg $\mathrm{t}$, welcher, eventuell mit der Verdünnungszahl multiplicirt; den (relativen) Farbstoffgehalt $f$ des Filtrates ausdrückt. f dividirt durch die Constante $3 \mathrm{c}^{2}$ (in diesem Falle 15,3) gibt somit die Leistungsfähigkeit der Kohle und zwar in Zahlén, die sich mit jeder anderen nach demselben Princip ausgeführten Werthbestimmung genau vergleichen lassen. Da $\frac{k}{V}=8 / 24=1 / 3$, so ist $\mathrm{j}=\frac{\mathrm{f}}{3 \mathrm{c}^{2}}$.

Die Methode zur Untersuchung pyrogener Gase, nach welcher Berthelot's bekannte Leuchtgasanalysen*) ausgeführt sind, hat derselbe, einem mehrseitig geäusserten Wunsche Folge leistend, nunmehr veröffentlicht. **)

A. Accessorische Bestandtheile.

Ammoniak findet sich nur in sehr geringer Menge in dem über Wasser gesammelten Gase. Man bestimmt es, indem man letzteres durch verdünnte Schwefelsäure streichen lässt, deren alkalimetrischer Titer vor und nach dem Versuche festgestellt wird. ***) Kohlensäure and Schwefelwasserstoff, sowie Sauerstoff und Wasserdampf werden nach den bekannten absorptiometrischen Methoden bestimmt. Der meist in geringer Menge vorhandene Schwefelkohlenst off wird durch wässeriges Kali nur ausserordentlich langsam aufgenommen. Mạn absorbirt ihn (sowie vorhándes K o hl ens to f f o x y sulfid) leicht durch ein einen Augenblick in Alkohol getauchtes Stück festes Aetzkali. Der hiernach etwa im Gase zurückbleibende Alkoholdampf muss durch längere Berührung des ersteren mit geschmolzenem Chlorcalcium entfernt werden. (Der Stickst off findet sich als Rückstand nach einer Verbrennungsanalyse).

Nachdem diese Gase entfernt oder bestimmt sind, wird zur Analyse der Kohlenwasserstoffe geschritten.

*) Zur Analyse des Leuchtgases vergleiche diese Zeitschrift 2, 441; 4, 231 ; †, 58, 360, 371; 10, 246, 495; 14, 47; 15, 122, 175; 16, 1, 24, 76; 17, 515.

**) Bull. soc. chim. de Paris [N. S.] 27, 155. Compt. rend. 83, 1256.

***) Vergleiche die Bemerkung von H. Fresenius, diese Zeitschr. 12, 331. 